\section{Sentence interpretation strategies in emergent bilingual children and adults*}

ILIANA REYES

University of Arizona

ARTURO E. HERNÁNDEZ

University of Houston

\begin{abstract}
This study examined sentence processing in emergent bilingual children and young adults in both English (second language - L2) and Spanish (first language - L1). One hundred participants from five different age groups $(5 ; 4-7 ; 11$, 8;0-10;11, 11;2-13;11, 14;0-16;8 years, and college-age adults) participated in this study. An online sentence interpretation paradigm was used to explore participants' processing patterns. Results of both choice and reaction time experiments provide new information about consolidation and "in between" strategies for Spanish-English bilinguals; on the use of the distribution of local vs. topological cues (namely early reliance on word order in both languages, followed by an integration of late-emerging subject-verb agreement cues from 11 to 13 years of age). The nature of these syntactic strategies and their implications for developmental theories of bilingualism are discussed.
\end{abstract}

\section{Introduction}

Language comprehension involves the integration of different linguistic input and the configuration of mental models (Johnson-Laird, 1983; Gernsbacher, 1990). Whether they do so consciously or not, learners need to pay attention to and integrate specific linguistic information in order to become competent speakers of their native language. Slobin (1985) has proposed a set of Operating Principles (OPs), which are universal strategies that guide children to pay special attention to the most regular and consistent morphosyntactic information in their native language (e.g. case marking, verb endings). Children must first identify the consistencies between semantic, word order, and morphological cues in their language, then use these for sentence interpretation (Bates and MacWhinney, 1989). Bilingual children are faced with the same task, but because they speak two languages they face greater challenges than monolingual speakers. Children are able to figure out specific morphological and syntactic rules in one language. What happens, though, when a child learns two or more languages? Does

\footnotetext{
* We dedicate this article to our mentor, Liz Bates, who introduced us to and guided us through the exploration of psycholinguistic processes in bilingual populations.

We thank Dan Slobin, and two anonymous reviewers for many constructive comments on previous versions of this paper. We would also like to thank Kain Sosa and Rehana Salahuddin for technical support, and to Paula Bautista for child testing. Finally, we are grateful to the children, their parents, and families who were so enthusiastic during their participation in this study. This research was partially supported by an LMRI grant (001G-SD) and the grant entitled 'Aging and Bilingualism' (NIA Grant \# 5-R01-AG13474-03).
}

the child apply separate strategies to the two languages or somehow meld them into one interpretation system? Based on studies of bilingual adults, bilinguals use different linguistic strategies depending on several variables, such as age of second language acquisition and on the strength of the linguistic cues present in each of their languages. Bilinguals learn to integrate cues from both languages, sometimes applying the rules from their first language (L1) to their second language (L2), at other times using a specific set of rules for each language, and still other times using an "amalgamation" of strategies (Wulfeck, Juarez, Bates and Kilborn, 1986; Kilborn, 1989; Liu, Bates and Li, 1992; Hernández, Bates and Avila, 1994; Hernández, Sierra and Bates, 2000).

Most studies exploring bilingual development have focused on lexical development (e.g. Pearson and Fernandez, 1994; Kohnert, Bates and Hernández, 1999), or pragmatic and communicative development (Lanza, 1997; Deuchar and Quay, 2000; Genesee, 2002; Reyes, 2004), rather than on syntactic development (but see Kail, 2004; Serratrice, Sorace and Paoli, 2004).

In this study, we were interested in exploring the morphosyntactic strategies of children who are EMERGENT bilinguals (i.e. dominant in Spanish and beginning to learn English) and in applying the predictions of the competition model (CM) of Bates and MacWhinney (1989) to this new domain of bilingual development. The bilingual children in this study are acquiring their two languages sequentially. They acquire their native language (Spanish) at home, then systematically learn their second language (English) when they start attending preschool or kindergarten. The term emergent bilinguals is used with this population because L2 competence is 
developing in parallel with L1 development during their first years of schooling. One important question in this domain is whether emergent bilinguals use the same linguistic processes for sentence interpretation regardless of the language being spoken. To address this question, the current study investigated the patterns of children's sentence interpretation strategies using an online version of the sentence interpretation (SI) task.

\section{Cross-linguistic research and the competition model}

This study is based on more than twenty-five years of cross-linguistic research using the SI task to study the grammatical strategies used by different typical language learners (adults, children, and bilingual speakers) and atypical populations (people with aphasia or Alzheimer's disease) (e.g. Fraser, Bellugi and Brown, 1963; Slobin, 1966; Slobin and Bever, 1982; MacWhinney, Pleh and Bates, 1985; McDonald, 1986; Wulfeck et al., 1986; Bates, Friederici and Wulfeck, 1987; Bates and MacWhinney, 1989; Hernández, Sierra and Bates, 2000). In the SI task, participants are presented with strings of two concrete nouns and a transitive action verb, containing syntactic, semantic, and morphological information that cue various competing or converging interpretations. The participant's task is to choose the agent of the sentence. The choice of noun indicates which sentence interpretation cues are most salient to that person. The findings from different sentence interpretation studies show dramatic crosslinguistic differences in the cues listeners rely on for sentence interpretation. For example, adult English speakers rely overwhelmingly on canonical ${ }^{1}$ word order (Bates and MacWhinney, 1989). Hindi speakers, in contrast, rely on noun animacy as an interpretation strategy (Vaid and Pandit, 1991), whereas Italian and Spanish adult speakers rely mostly on subject-verb agreement, followed by noun animacy and word order (Kilborn, 1989; Hernández et al., 1994).

One of the models proposed to account for these cross-linguistic differences in sentence interpretation is the competition model (CM) of Bates and MacWhinney (1989). The CM is an interactive-activation framework that accounts for quantitative as well as qualitative variations in performance across different languages. The model is based on two basic notions: cue validity and cue cost. CuE VALIDITY refers to the information value of a given phonological, lexical, morphological, or syntactic form within a particular language. CUE COST refers to the amount and type of processing required for the activation of a given linguistic form, when cue validity is held constant. Based on these two notions, the CM predicts that sentences where cues converge to yield a

\footnotetext{
1 Canonical word order is the default word order interpretation in a given language; for example, in English it is SVO.
}

single interpretation should be understood more easily and processed more quickly than sentences where some cues point to one interpretation and other cues point to a different one. These two factors co-determine the dynamic process by which word form and meaning are activated and mapped onto each other in real time. (For further discussion of the CM, refer to Bates and MacWhinney, 1989; and for a very recent review see Devescovi and D'Amico, 2005.) In the case of young emergent bilinguals we do not yet know how they develop these representations and what processing strategies they use for sentence interpretation. Of particular interest to us is what the role of cue cost is in developing sentence interpretation strategies and how this may change with time.

\section{Studies of sentence interpretation}

Evidence from studies suggests that monolingual adult speakers show a strong preference for the most valid syntactic cues in their native language. For English monolinguals, word order is the most valid cue, used from an early age; in adulthood subject-verb agreement becomes the second most important cue. By contrast, Italian and Spanish monolingual adults show a strong preference for subject-verb agreement, followed by word order and animacy cues (Bates and MacWhinney, 1989).

From the CM perspective, child language development involves not only learning rules and mappings, but "a gradual process of the tuning of these mappings to fit the profile of strengths and weaknesses reflected in the linguistic input" (Dick, Wulfeck, Krupa-Kwiatkowski and Bates, 2004, p. 361). Based on results of previous SI studies with adults, the $\mathrm{CM}$ predicts that children acquire sentence interpretation strategies in an order that is predictable from the cue validity of the grammatical structures in the adult language. However, evidence from developmental cross-linguistic studies modifies this prediction, showing that cue cost may alter the development of these strategies (Kail and Charvillat, 1988; Devescovi, D'Amico, Smith, Mimica and Bates, 1998). For example, sentence interpretation studies with typical and atypical Italian, French, and German speaking children have found that they progress from using LOCAL to using TOPOLOGICAL ${ }^{2}$ cues when interpreting sentences (Kail and Charvillat, 1988; Devescovi et al., 1998; Lindner, 2003). Specifically, these children initially tend to use word order (a LOCAL CUE) as a cue for sentence meaning, then shift to integrate the use of TOPOLOGICAL CUES that are available

\footnotetext{
2 Slobin (1979) refers to morphological agreement cues (e.g. subjectverb agreement) as DISTRIBUTED or TOPOLOGICAL CUES, which are harder than local cues to process because they are distributed across several sentence elements. In contrast, LOCAL CUES can be interpreted immediately, because the necessary elements are adjacent to each other (Kail, 1989).
} 
in their native languages. Kail (1989) and Devescovi et al. (1998) have accounted for this pattern by hypothesizing that topological cues make greater demands on shortterm memory and require additional mental operations to compare and cross-reference the elements held in memory. Other studies have confirmed that morphological cues such as subject-verb agreement have little effect on sentence interpretations of typical and atypical Englishspeaking children - because it has relatively low cue validity and has a higher cost in terms of memory load (Thal and Flores, 2001; Dick et al., 2004). Evidently, the development of morphological cues is slower than syntactic cues due to cue cost and limitations on children's processing ability. ${ }^{3}$

More recently, using an online SI task, Reyes (2003) found that young Spanish monolingual Mexican children also develop subject-verb agreement strategies relatively late. Specifically, 5 - to 10 -year-olds showed a strong effect of word order that by age 11 shifts to a preference for subject-verb agreement. The fact that word order is used first for sentence interpretation suggests again that CUE COST plays a very important role early in grammatical development and that children make earlier use of LOCAL cues than TOPOLOGICAL ones due to the higher cost of the latter. Over time cue validity wins out, allowing speakers of languages like Spanish to use the subject-verb agreement cue, which is the most valid cue in interpreting the language (Hernández, Bates and Avila, 1994). In terms of real-time processes, Reyes observed an increase in reaction time (RT) across age groups, such that the 14- to 16-year-olds and adults were actually slower to interpret sentences than were any of the younger children. This finding confirmed previous findings by Hernández et al. (1994) showing that Spanish monolingual adults pay a higher cost to process and consolidate competing cues, a cost reflected in slower RTs. These results are particularly relevant to the present study because they provide the first baseline data for typical SI development of monolingual Spanish-speaking children, giving us a basis of comparison with Spanish-English bilingual children.

So far, findings from these developmental studies confirm the importance of semantic and syntactic cues; specifically, whether typical or atypical language learners, children initially rely on word order and animacy. More complex morphosyntactic cues (case marking and subjectverb agreement, among others) are developed later (see Lindner, 2003, for a recent review). Taken together, these studies suggest that there is no single universal sequence in which children acquire grammatical cues.

3 In addition, SI studies with aphasic patients show that grammatical breakdown is, at least to some extent, determined by the strength of the cues in the language, in that the most valid cues are retained by the impaired population (Wulfeck, Juarez, Bates and Kilborn, 1986).
Instead, cue validity and cue cost interact to determine the development of grammatical strategies and sentence interpretation strategies by speakers of specific languages. From a bilingual developmental perspective, this raises an important issue in terms of the role of local versus distributed cues in children who are learning two languages. Specifically, we speculate on the role that CUE COST plays and how it aids in sentence interpretation of Spanish and English emergent bilinguals. In the next section, we review the available literature on adult bilinguals with a focus on English-Spanish bilinguals.

\section{Bilinguals and sentence interpretation}

Early studies on adult bilinguals' development of sentence interpretation ability identified four sentence interpretation strategies: (1) AMALGAMATION, the use of those cues that are moderately strong in both languages (e.g. Spanish-English bilinguals in Wulfeck et al., 1986); (2) FORWARD TRANSFER, the use of L1 processing strategies in L2 (e.g. German-English bilinguals in Kilborn, 1994); (3) BACKWARD TRANSFER, the use of L2 processing strategies in L1 (e.g. Chinese-English bilinguals in Liu et al., 1992); and (4) DIFFERENTIATION, the use of distinct strategies in each language (e.g. Spanish-English bilinguals in Hernández et al., 1994). Out of all these patterns, amalgamation has been the predominant pattern in studies that have focused on early bilinguals who use both languages in everyday activities (e.g. Hindi-English bilinguals in Vaid and Pandit, 1991; Spanish-English bilinguals in Wulfeck et al., 1986 and Hernández et al., 1994).

We now turn to the particular findings of SpanishEnglish bilinguals in a study conducted by Hernández et al. (1994). For comparison purposes, they also studied Spanish and English monolinguals. Before describing their study in detail, we first explain some selected characteristics of the English and Spanish languages that enable us to understand unique sentence interpretation patterns in this population.

In both English and Spanish, SVO is the most frequent word order. Word order is more variable in Spanish than in English, however, as Spanish allows several different word orders, many of which are ungrammatical or sound awkward in English. Because of this great variation, word order is a weak and unreliable cue to thematic roles in Spanish. Instead, Spanish relies on morphological agreement (such as subject-verb and noun-adjective gender and number) and other grammatical cues (e.g. accusative preposition $a$, gender agreement) for sentence interpretation (see example 1). Another characteristic of Spanish is that it is a pro-drop language in which subjects may be omitted in finite clauses (see Sebastian and Slobin, 1994, for further discussion), whereas English is not (see example 2). 
(1) La niña besó a la gata.

"The girl kissed to $\mathrm{accusative} \mathrm{preposition}$ the $\mathrm{fem} \mathrm{article}_{\text {cat." }}$

(2) Estoy lavando el carro.

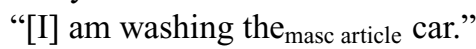

English speakers, on the other hand, rely less on morphological information and more heavily on word order. Subject-verb-object (SVO) word order is the canonical and most frequent word order used in English; the VOS non-canonical word order develops later, around age nine, among English speaking children (Von Berger, Wulfeck, Bates and Fink, 1996). As Bates and MacWhinney (1989) point out, these second-noun strategies might reflect a partial fit to other word order options in the language (e.g. imperative constructions such as "Bring your shoe, Lisa" could support a VOS interpretation).

In their SI study in Spanish and English, Hernández et al. (1994) found, as expected, that monolinguals relied on those cues that were the most valid in their language when identifying the role of agent. Spanish monolinguals used subject-verb agreement as the main cue for agent choice, whereas English monolinguals used word order. The results for Spanish-English bilinguals, though, revealed a pattern of amalgamation, in which listeners used a combination of processing strategies from both languages during sentence interpretation (i.e. agreement was by far the strongest cue, but canonical word order (SVO) was the second strongest strategy and interacted with animacy cues). This information proved useful in the present study because it helped us predict the degree to which bilingual children might rely on one cue over another when presented with an SI task. However, findings from these previous studies provide little information about how bilinguals arrive at this point and what the developmental trajectory of these syntactic strategies looks like. This brings us to the purpose of the present study.

\section{Hypotheses of the present study}

The present study investigated the emergence of morphosyntactic sentence interpretation patterns in emergent bilinguals, with the same online SI task used in previous studies. The following are the main research questions:

1. What interpretation strategies do Spanish-English emergent bilinguals use in real time when presented with grammatical and semi-grammatical sentences?

2. At what age and in what fashion do Spanish-English bilinguals make use of local versus distributed cues for sentence interpretation?

Results from previous studies have shown that adults' use of cue validity is not strictly predictive of children's sentence interpretation strategies. Moreover, as previously stated, in monolingual populations cue cost factors interact with cue validity, making it hard for the $\mathrm{CM}$ to predict or explain this variability in sentence processing strategies by bilinguals. Based on previous results, we predict that both language-specific cues (cue validity) and language general cues (cue cost) could provide several outcomes among our emergent bilinguals:

1A. EARLY USE OF LOCAL CUES SUCH AS WORD ORDER. We expect a strong effect of canonical word order in these young bilinguals' processing strategies. That is, cue cost effects will interact to delay the development of valid cues. Specifically, we would expect for word order to be the strongest cue used for sentence interpretation in both languages for the youngest age groups. This pattern has been found in a number of developmental studies with English, Spanish, and Italian monolinguals (Bates et al., 1984; Von Berger et al., 1996; Devescovi et al., 1998; Reyes, 2003).

1B. Delayed use of Distributed CUES SUCh AS SUBJeCtVERB AGREEMENT COMPARED TO WORD ORDER. We anticipate a delay in the use of the subject-verb agreement cue by these Spanish-English bilingual children, due to the greater demands on children's short-term memory to process and perceive topological cues and because they require some additional mental operations for comparing and cross-referencing the elements stored in memory. Among bilingual children sensitivity to subject-verb agreement may emerge later than among Spanish monolingual children because (1) Spanish speakers are slower to develop word order as a cue, given that it is not very valid and (2) that the children need to sort and integrate the cues present in their two languages. For adult bilinguals, we expect to replicate the findings of Hernández et al. (1994), which indicate that bilingual college-age adults use strategies from both of their languages. Since bilinguals are in a sense 'amalgamating' syntactic strategies from both languages, we cannot assume that their linguistic processes will parallel those of their monolingual counterparts.

1C. CANonical versus NON-CANONicAl WORD ORDer. We expect the canonical SVO first-noun strategy to appear first followed by the VOS and OSV strategies. We expect this order to appear in both languages because that has been the pattern reported before. However, the timing of this pattern may be mediated by language-specific cues.

Our predictions for reaction time (RT) follow the principles of the CM:

2A. RT COSTS FOR COMPETITION AND CONVERGENCE. RTs should be the fastest when subject-verb agreement 
and word order cues converge, and the slowest when they compete (i.e. each cue points to a different noun as agent). We leave open the possibility that the magnitude of this competition or convergence effect will increase with age and will depend on the word order and language being processed.

2B. RT IN RELATION TO LANGUAGE. In relation to language, we expect to replicate the findings of Hernández et al. (1994) that processing of Spanish sentences would be slower that English sentences. The RT difference may be due to the fact that the Spanish stimulus words might contain significantly more syllables than the English words due to the structure of the language. This pattern will also be affected by the specific word orders and agreement of the sentences. For example, RTs should be fastest for the canonical NVN word order (SVO interpretation) than for the less common VOS and OSV orders.

2C. RT IN RELATION TO AGE. The results from previous developmental studies provide strong evidence for an increase in competition and convergence effects with age, whereby adults pay a higher cost than young children to process and consolidate cues, which is reflected in slower RTs. Therefore, we expect two possible patterns. First, emergent bilingual children would become more efficient at processing Spanish and English sentences as they develop proficiency in their L2. Second, RTs may SLOW DOWN during middle childhood, indicating a process of consolidating strategies in each of their languages. This slowdown would be analogous to the slowdown observed among monolingual children when they process competing cues (Von Berger et al., 1996; Dick et al., 2004).

In summary, the present study should help determine language-specific influences on subject-verb agreement and word order cues in bilingual language processing. We hope that the combination of RT and sentence interpretation data will provide insights into the development of syntactic strategies in Spanish-English bilinguals and into the interplay of their two linguistic systems.

\section{Method}

\section{Participants}

A total of 100 participants were included in the current study. Participants were all right handed, ranged in age from $5 ; 4$ to $23 ; 2$, and were divided into five different groups ( $n=20$ for each age group): $5 ; 4-7 ; 11,8 ; 0-10 ; 11$, $11 ; 2-13 ; 11,14 ; 0-16 ; 8$, and $18 ; 2-23 ; 4$ years (the last group referred to hereafter as college-age adults). Our younger participants were recruited throughout Santa
Barbara County and were given gift certificates (e.g. meal certificates, movie tickets) as compensation for their participation. College-age participants were enrolled undergraduate students at the University of California, Santa Barbara (UCSB), and their compensation was either $\$ 5.00$ per hour of participation or class credit in undergraduate psychology courses.

\section{Language questionnaire and background information}

College-age participants filled out a questionnaire about their language history; for children, a parent filled out a developmental and language screening questionnaire regarding the child. These questionnaires included information about age of first exposure to L2, frequency and relative ease of use of L1 and L2 (e.g. among family, friends, and teachers), and formal language education (a copy of the questionnaire is published as an appendix to Liu et al., 1992). In addition, parents participated in a brief interview with the researcher in order to clarify the information they provided. Children passed a puretone hearing screening at $25 \mathrm{~dB}$ HL (ANSI, 1989) at 1000,2000 , and $4000 \mathrm{~Hz}$. Any child suspected of having a language, learning, or developmental delay/disorder, as indicated by parental report or poor academic performance, was excluded from the study. The experimental results of six children were excluded from subsequent analysis due to parental concerns regarding the child's academic abilities (e.g. verbal skills or academic performance). All of the participants learned Spanish as their first language, and parents reported Spanish to be the primary language of communication at home. All participants began the systematic learning of English (L2) in school between the ages of 4 and 6 years. All participants were administered the Boston Naming Test (Kaplan, Goodglass and Weintraub, 1983) and the Spanish and English versions of the Peabody Picture Vocabulary Test (Dunn, Dunn, Robertson and Eisenberg, 1981; Dunn, Padilla, Lugo and Dunn, 1986), first in Spanish and then in English. The purpose of administering these tests was to obtain an index of naming ability (expressive vocabulary) and comprehension ability (receptive vocabulary) in each language (L1 and L2). Table 1 provides a summary of background information and mean test scores for each age group.

\section{Experimental stimuli and design}

The experimental stimuli consisted of 54 sentences in Spanish and English. The sentence stimuli were generated by random selection from a pool of 12 animate nouns (all animals) and 15 transitive action verbs. We used only animate nouns to control for possible semantic effects on sentence interpretation. Because we were working with children in two languages and we wanted to keep 
Table 1. Participants' language background (mean scores except as indicated)

\begin{tabular}{|c|c|c|c|c|c|c|c|c|}
\hline Group & $\begin{array}{l}\text { Female/ } \\
\text { Male }(n)\end{array}$ & Age & $\begin{array}{l}\text { Age of first } \\
\text { formal } \\
\text { English } \\
\text { experience }\end{array}$ & $\begin{array}{l}\text { Years of } \\
\text { formal } \\
\text { English } \\
\text { experience }\end{array}$ & $\begin{array}{l}\text { Boston } \\
\text { Naming } \\
\text { Test } \\
\text { (English) }\end{array}$ & $\begin{array}{l}\text { Boston } \\
\text { Naming } \\
\text { Test } \\
\text { (Spanish) }\end{array}$ & $\begin{array}{l}\text { Peabody } \\
\text { Vocabulary } \\
\text { Test } \\
\text { (English) }\end{array}$ & $\begin{array}{l}\text { Peabody } \\
\text { Vocabulary } \\
\text { Test } \\
\text { (Spanish) }\end{array}$ \\
\hline 5- to 7 -year-olds & $17 \mathrm{~F} / 3 \mathrm{M}$ & 6.7 & 4.9 & 1.8 & 15.72 & 13.52 & 49.63 & 45.31 \\
\hline 8- to 10 -year-olds & $11 \mathrm{~F} / 9 \mathrm{M}$ & 9.5 & 5.2 & 4.5 & 25.93 & 22.93 & 81.68 & 66.88 \\
\hline 11 - to 13 -year-olds & $10 \mathrm{~F} / 10 \mathrm{M}$ & 12.4 & 5.3 & 6.7 & 27.59 & 25.63 & 99.90 & 81.90 \\
\hline 14 - to 16 -year-olds & $11 \mathrm{~F} / 9 \mathrm{M}$ & 16.3 & 5.2 & 10.9 & 31.7 & 25.35 & 114.57 & 89.42 \\
\hline Adults (18-23 years) & $17 \mathrm{~F} / 3 \mathrm{M}$ & 18.87 & 5.3 & 14.3 & 42.3 & 24.8 & 144.45 & 106.90 \\
\hline
\end{tabular}

Table 2. Sample stimuli for each of the 9 sentence types in the experiment

\begin{tabular}{lll}
\hline \hline Sentence type & English & Spanish \\
\hline NVN, Ag1 & The dog is chasing the horses. & El perro está correteando los caballos. \\
NVN, Ag0 & The dog is chasing the horse. & El perro está correteando el caballo. \\
NVN, Ag2 & The dog are chasing the horses. & El perro están correteando los caballos. \\
VNN, Ag1 & Is chasing the dog the horses. & Está correteando el perro los caballos. \\
VNN, Ag0 & Is chasing the dog the horse. & Está correteando el perro el caballo. \\
VNN, Ag2 & Are chasing the dog the horses. & Están correteando el perro los caballos. \\
NNV, Ag1 & The dog the horses is chasing. & El perro los caballos está correteando. \\
NNV, Ag0 & The dog the horse is chasing. & El perro el caballo está correteando. \\
NNV, Ag2 & The dog the horses are chasing. & El perro los caballos están correteando. \\
\hline \hline
\end{tabular}

the sessions short, excluding animacy allowed us to collect data in both languages in a manner which avoided fatigue from children and minimized our participants' dropout rate. Given that 'animacy' is the cue that least distinguishes Spanish from English we felt that excluding it would allow us to accomplish our goals without sacrificing our ability to see cross-language and betweengroup differences.

The present progressive form of the verb was used in all sentence stimuli in order to facilitate comparison of results with those of previous sentence interpretation studies (see Appendix A for a complete list of nouns and verbs used). There were three independent variables:

1. Language (sentences were presented auditorily in either Spanish or English).

2. Word order (NVN: noun-verb-noun, VNN: verbnoun-noun, NNV: noun-noun-verb).

3. Subject-verb agreement morphology: agreement between noun(s) and verb (Ag1: the verb agrees with the first noun in the sentence, Ag2: the verb agrees with the second noun, or $\mathrm{Ag} 0$ : the verb form is ambiguous).

The combination of the two variables (word order and subject-verb agreement), each having three possibilities, yielded a total of nine possible sentence types. Six sentence stimuli were generated for each type of sentence, thus resulting in a total of 54 sentences in each language. Each sentence consisted of two nouns, each preceded by a definite article, plus a verb (see Table 2 for sample sentence stimuli). As can be seen from the sample stimuli, the six sentences within each group varied according to the three agreement conditions. The combination of agreement conditions and word order cues yielded grammatical and semi-grammatical sentences. The use of both grammatical and semi-grammatical stimuli is common in this paradigm and sentence processing strategies have been shown to be comparable for both types of stimuli (see Li, 1996, for more discussion).

\section{Apparatus}

Visual and auditory stimui were presented using the PsyScope experimental shell from Carnegie Mellon University (Cohen, MacWhinney, Flatt and Provost, 1993) on a 15-inch Macintosh Motorola StarMax 3000/18 computer. The participants listened to the auditory stimuli for the Peabody Picture Vocabulary Test and the sentence presentations through a set of Optimus Pro$50 \mathrm{MX}$ headphones. The stimuli were recorded by a male speaker fluent in Spanish and English in a soundproof 
booth using the SoundEdit 16 software package. The auditory stimuli were digitized at 16-bit, 22k sampling. Subjects were given a $5000 \mathrm{~ms}$ response window. All reaction times were recorded on a Carnegie Mellon University button box.

\section{Procedure}

Each subject participated in two individual sessions, receiving at each session sentences in only one language. The order of presentation of the languages across the two sessions was counterbalanced across participants; half the subjects were tested in Spanish first and half in English first. The young adults were tested individually in the psycholinguistic laboratory at UCSB. The children were tested individually, either at home or in the conference room of the Isla Vista Teen Center in Santa Barbara.

There were three sets of trials: baseline, practice, and experimental. Participants received instructions prior to each set of trials in the same language used for the sentence stimuli in that session. Initially, a baseline of 30 trials was administered to obtain a rate of response to visual stimuli. The baseline consisted of faces presented on either the left or right side of the computer screen. Participants pressed one of two buttons to indicate the position of the face on the screen. After the baseline trial, all participants were given a practice set of six sentences that illustrated each of the different conditions of the experiment; this was done to ensure that the children understood the task. Participants were instructed in the language of the session to listen carefully to each sentence and to decide as quickly as possible which of the two nouns was the actor in the sentence. Before each sentence was presented, the two nouns used in it were named and a picture of each was shown on the screen, side by side, counterbalanced with sentence order. Participants had to decide which of the two nouns performed the action in the sentence and had to press the button that corresponded to the side of the screen where that animal was pictured. Only responses obtained within the response window $(5000 \mathrm{~ms})$ were included in the analysis. A total of $2 \%$ of responses were excluded from the final analysis because they failed to fall within the given response window.

\section{Data analysis}

The scoring procedure used in this study was based on previous studies of sentence interpretation to facilitate crossstudy comparison of results (Bates and MacWhinney, 1989; Hernández et al., 1994). Because there are no right or wrong answers for many of the sentence types in this paradigm, we do not analyze percentage correct. Instead, we discuss the results in terms of the percentage of stimuli in which the participant chose the first noun as the agent (percentage first-noun choice) and in terms of reaction
Table 3. Between-groups ANOVA

\begin{tabular}{|c|c|c|c|}
\hline \multirow[b]{2}{*}{ Source } & \multirow[b]{2}{*}{ df } & \multicolumn{2}{|c|}{$F$ ratio } \\
\hline & & Choice & RT \\
\hline Group & 4 & $4.52^{* *}$ & 0.99 \\
\hline Language & 1 & $13.97^{* * *}$ & $419.40^{* * *}$ \\
\hline Word order & 2 & $123.05^{* * *}$ & $182.81^{* * *}$ \\
\hline Subject-verb agreement & 2 & $73.39^{* * *}$ & 2.71 \\
\hline Group $\times$ word order & 8 & $2.62^{* *}$ & $4.98^{* * *}$ \\
\hline Group $\times$ subject-verb agreement & 8 & $11.49^{* * *}$ & 1.01 \\
\hline Language $\times$ group & 4 & $2.50^{*}$ & $4.29^{* *}$ \\
\hline Language $\times$ word order & 2 & $23.14^{* * *}$ & $3.39^{*}$ \\
\hline $\begin{array}{l}\text { Language } \times \text { subject-verb } \\
\text { agreement }\end{array}$ & 2 & $3.65^{*}$ & 1.57 \\
\hline $\begin{array}{l}\text { Word order } \times \text { subject-verb } \\
\text { agreement }\end{array}$ & 4 & $8.49^{* * *}$ & $15.84^{* * *}$ \\
\hline Group $\times$ language $\times$ word order & 8 & $2.47^{*}$ & 0.670 \\
\hline $\begin{array}{l}\text { Group } \times \text { language } \times \\
\text { subject-verb agreement }\end{array}$ & 8 & 0.98 & 0.713 \\
\hline $\begin{array}{l}\text { Group } \times \text { word order } \times \\
\text { subject-verb agreement }\end{array}$ & 16 & $2.085^{* *}$ & $4.22^{* * *}$ \\
\hline $\begin{array}{r}\text { Language } \times \text { word order } \times \\
\text { subject-verb agreement }\end{array}$ & 4 & $5.12^{* * *}$ & $5.86^{* * *}$ \\
\hline $\begin{array}{l}\text { Group } \times \text { language } \times \text { word } \\
\text { order } \times \text { subject-verb } \\
\text { agreement }\end{array}$ & 16 & 1.16 & 1.12 \\
\hline
\end{tabular}

Group $n=20 ;{ }^{*} p<0.01 ;{ }^{* *} p<0.001{ }^{* * *} p<0.0001$.

time. For the percentage first-noun choice analysis, a score of 1 was assigned when participants chose the first noun, and 0 was assigned when they chose the second noun. Consequently, the closer to $100 \%$ a participant's score, the more often he or she selected the first noun, and the closer to $0 \%$ the more often he or she selected the second noun; a score of $50 \%$ (first and second nouns chosen with equal frequency) constitutes random performance.

\section{Results and discussion}

The first-noun choice and RT data were used to profile patterns of developmental change across age groups. First we present the cross-group analyses of the main effects and significant interactions. The data from all age groups were placed into a (5) group by (2) language by (3) word order by (3) subject-verb agreement analysis of variance (ANOVA), with age group as a between-subject variable and language, word order, and subject-verb agreement treated as within-subject variables. Table 3 summarizes the ANOVA analysis for noun-choice and RT data. In addition, we conducted a separate (2) language by (3) 


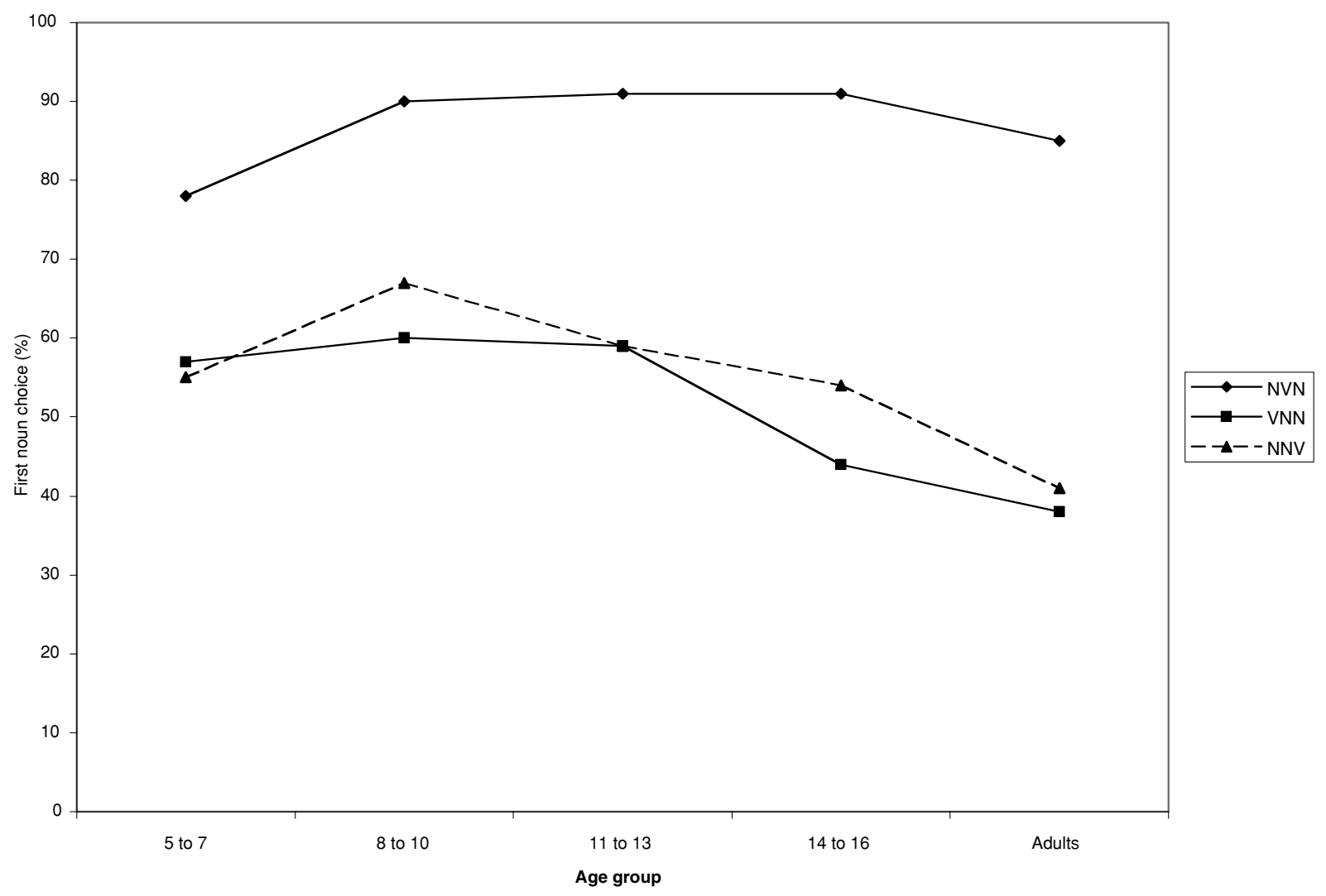

Figure 1. Percentage first-noun choice: Group by word order interaction.

word order by (3) subject-verb agreement ANOVA for each age group in order to confirm the developmental trend that emerged from the between-group comparisons. The results are summarized in Appendices B and C for noun choice and RT, respectively.

\section{Noun choice}

\section{Main effects}

The results for percentage first-noun choice yielded significant main effects for group, language, word order, and subject-verb agreement. The main effect of word order accounted for $57 \%$ of the experimental variance, whereas subject-verb agreement accounted for only $12 \%$. The strong effect of word order indicates that it is a valid cue for bilingual Spanish-English speakers across a wide age range. However, this effect decreases and interacts with subject-verb agreement cues as children get older.

\section{First- and second-order interactions}

For first-noun choice, the analysis revealed significant first-order interactions for group by word order, group by subject-verb agreement, group by language, and language by word order, as well as significant higherorder interactions involving language by word order by subject-verb agreement, group by word order by subjectverb agreement, and group by language by word order.

\section{Word order}

As illustrated in Figure 1, a significant interaction of group by word order reveals children's basic word order preference is NVN followed by VNN then NNV. These bilinguals display a strong preference for NVN sentences with SVO interpretation from the earliest age tested (5to 7-year-old group). However, differences appear across groups when interpreting the semi-grammatical sentences with non-canonical word orders. Whereas the 5- to 7through 11- to 13-year-olds show no second-noun bias in VNN and NNV sentences, in that they chose the first noun as the agent more than $50 \%$ of the time, there is evidence of a late-emerging second-noun strategy (VOS and OSV interpretations) for the 14- to 16-year-olds which begins to mirror adult performance.

This late-emerging second-noun strategy is also evident in the significant three-way interaction of group by language by word order, $F(8,190)=2.466, p<0.01$, where results reveal different patterns of performance according to word order and language. Figures $2 \mathrm{a}-\mathrm{c}$ present this three-way interaction, broken down by each of the three word-order types. 


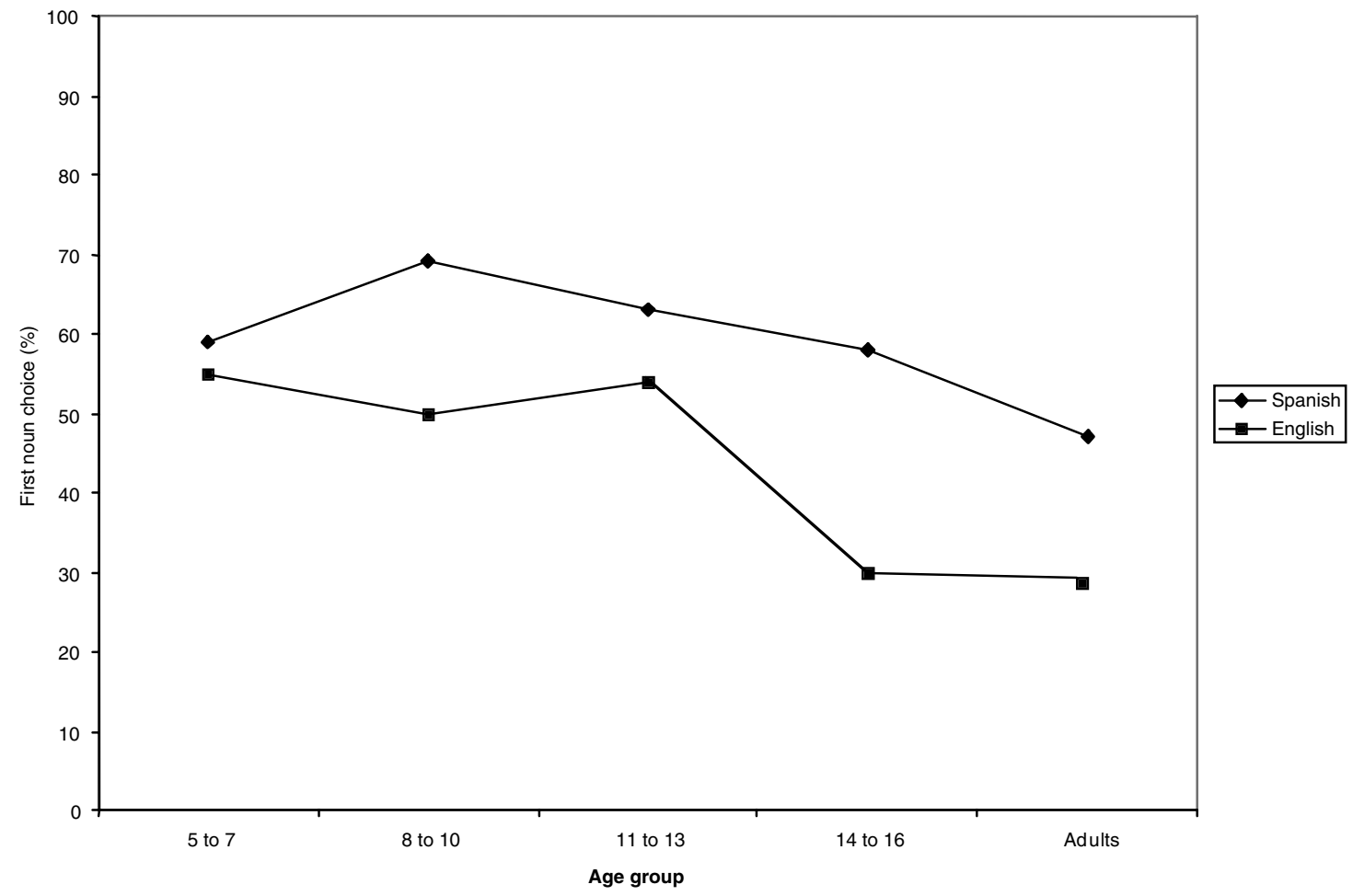

Figure 2a. Percentage first-noun choice: Group by language interaction for NVN sentences.

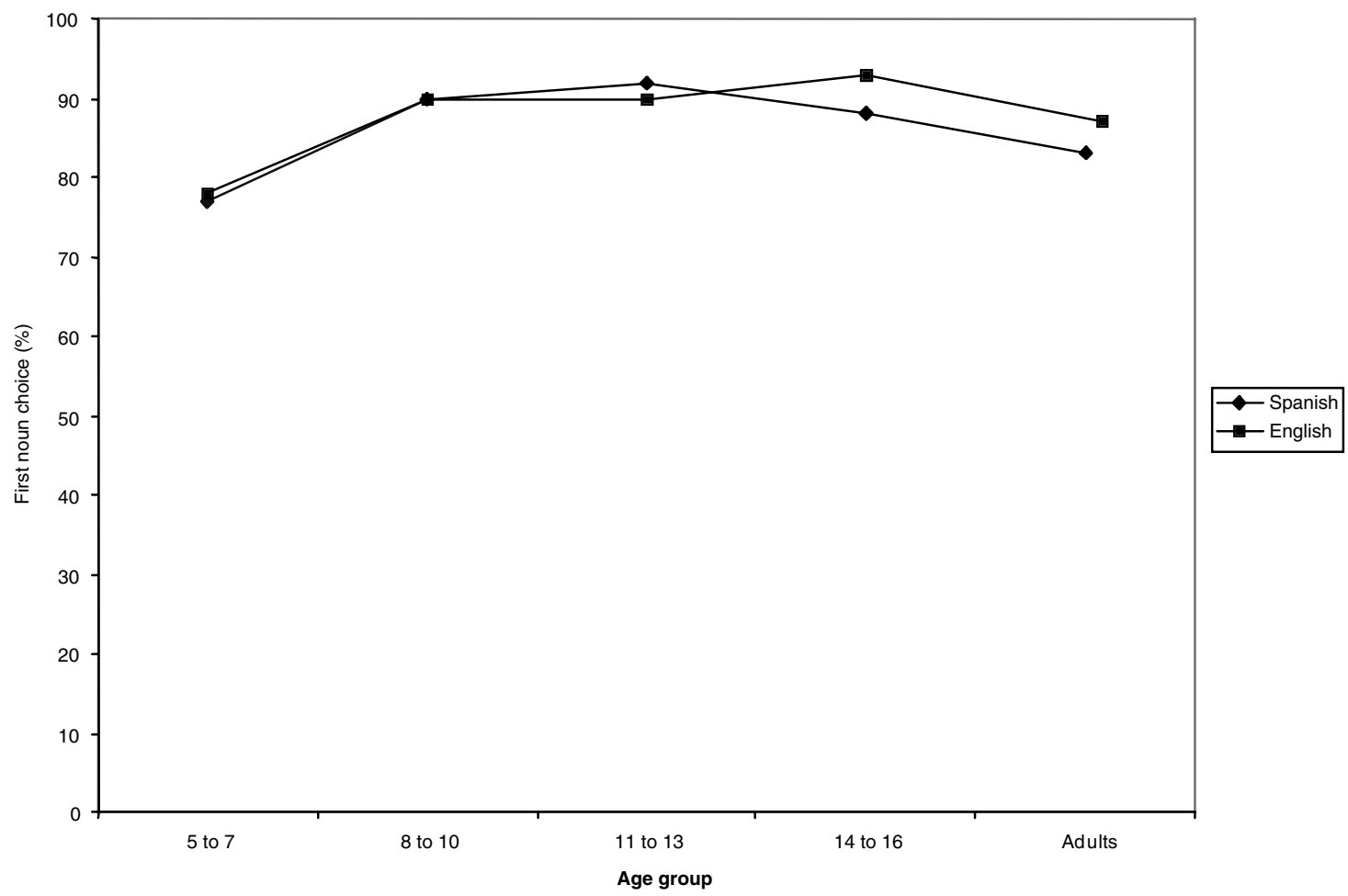

Figure 2b. Percentage first-noun choice: Group by language interaction for VNN sentences. 


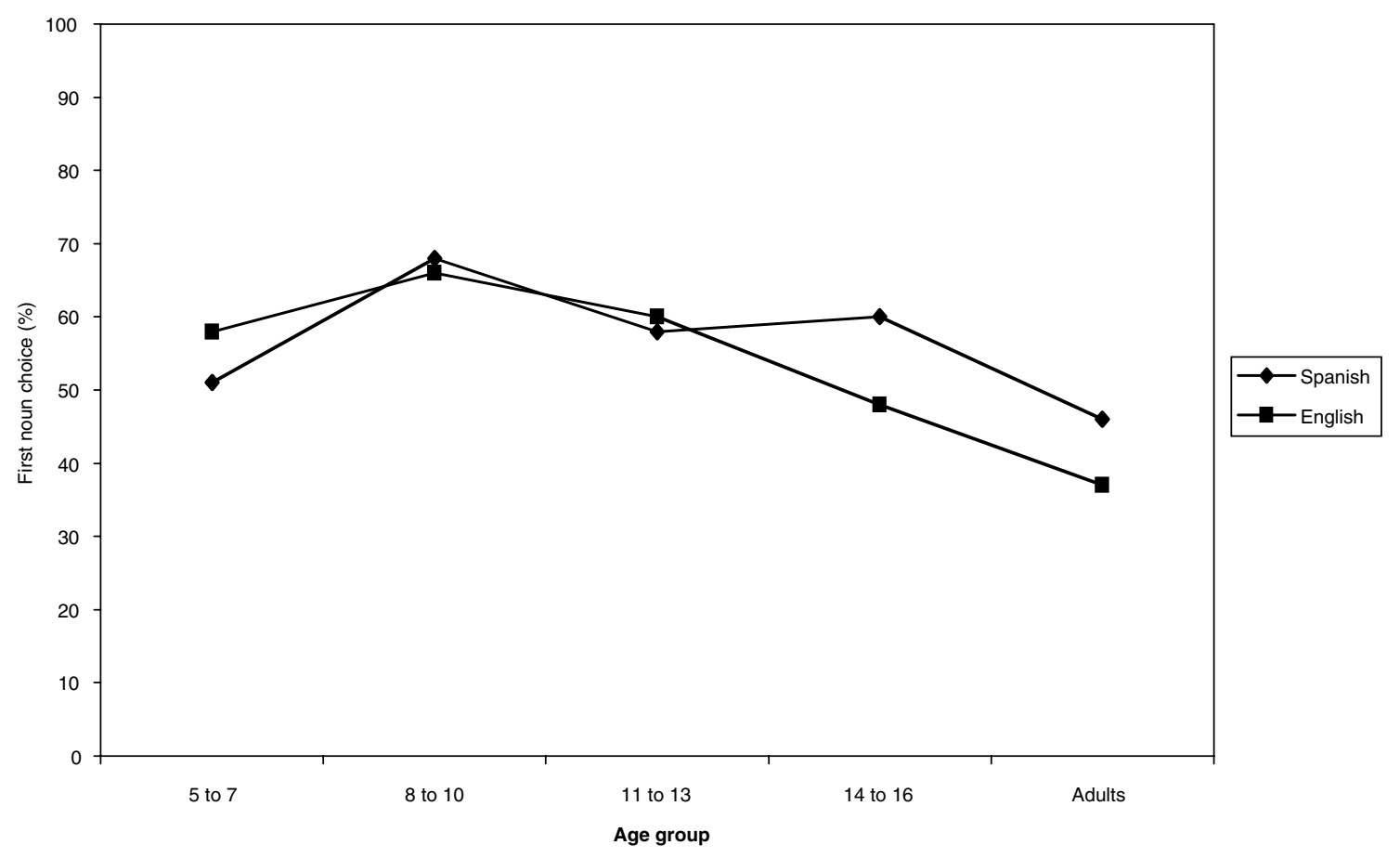

Figure 2c. Percentage first-noun choice: Group by language interaction for NNV sentences.

The results clearly show one significant developmental change from the 5- to 7-year-old group to the 8- to 10-year-old group: There was an increase from $78 \%$ to $90 \%$ preference for the first noun as agent for the NVN sentence type in both languages (see Figure 2a). This increase in first-noun choice illustrates that the children are able to focus on word order as the main linguistic cue when presented with sentences of the canonical type. In addition, this result demonstrates that canonical word order is a valid cue for sentence interpretation in both languages from an early age. For VNN sentences (see English and Spanish conditions in Figure 2b), the second-noun strategy emerged gradually across groups in Spanish, but the small numerical differences between groups are not significant. In English, by contrast, we observed the clear emergence of a second-noun strategy between the 11- to 13-year-old group and the 14- to 16 -year-old group, reflected by a sharp and significant decrease in first-noun choice, from $47 \%$ to $20 \%$. These results indicate that use of the second-noun strategy for interpreting non-canonical word orders is greater for English than for Spanish across development. In addition, these bilingual children never process VNN sentences as efficiently in Spanish as they do in English. The earlier emergence of the second-noun strategy in English among these bilinguals parallels the findings in the English monolingual literature (Von Berger et al., 1996).

Finally, for NNV sentences, we also observed a slow shift to the second-noun strategy. Children in the three younger age groups selected the first noun in about $68 \%$ of their responses (see Figure 2c); for this sentence type there were no significant differences by language, with both English and Spanish following the same pattern. This result might be interpreted as indicating an amalgamation pattern, where children apply the same strategy in both languages. There is a shift toward a second-noun strategy in both languages; however, it occurs at an earlier age in English (between the 11- to 13- and 14- to 16-year-olds) than it does in Spanish (between the 14- to 16-year-olds and adults). This age difference in the emergence of the second-noun strategy shows that the impact of cue cost changes according to language.

\section{Subject-verb agreement}

As seen from the previous interactions, these emergent bilingual children showed a strong preference for NVN word order with an SVO interpretation when word order is the only consideration. What happens when we add subject-verb agreement cues that either compete (e.g. verb inflection does not agree with the first noun) or converge (e.g. word order is canonical and the verb agrees with the first noun) with word order cues? To answer this question, we first looked at the interaction between group and subject-verb agreement. This significant interaction, illustrated in Figure 3, shows that subject-verb agreement has little influence among the 8- to 10-year-olds; however, its effect increases with age. 


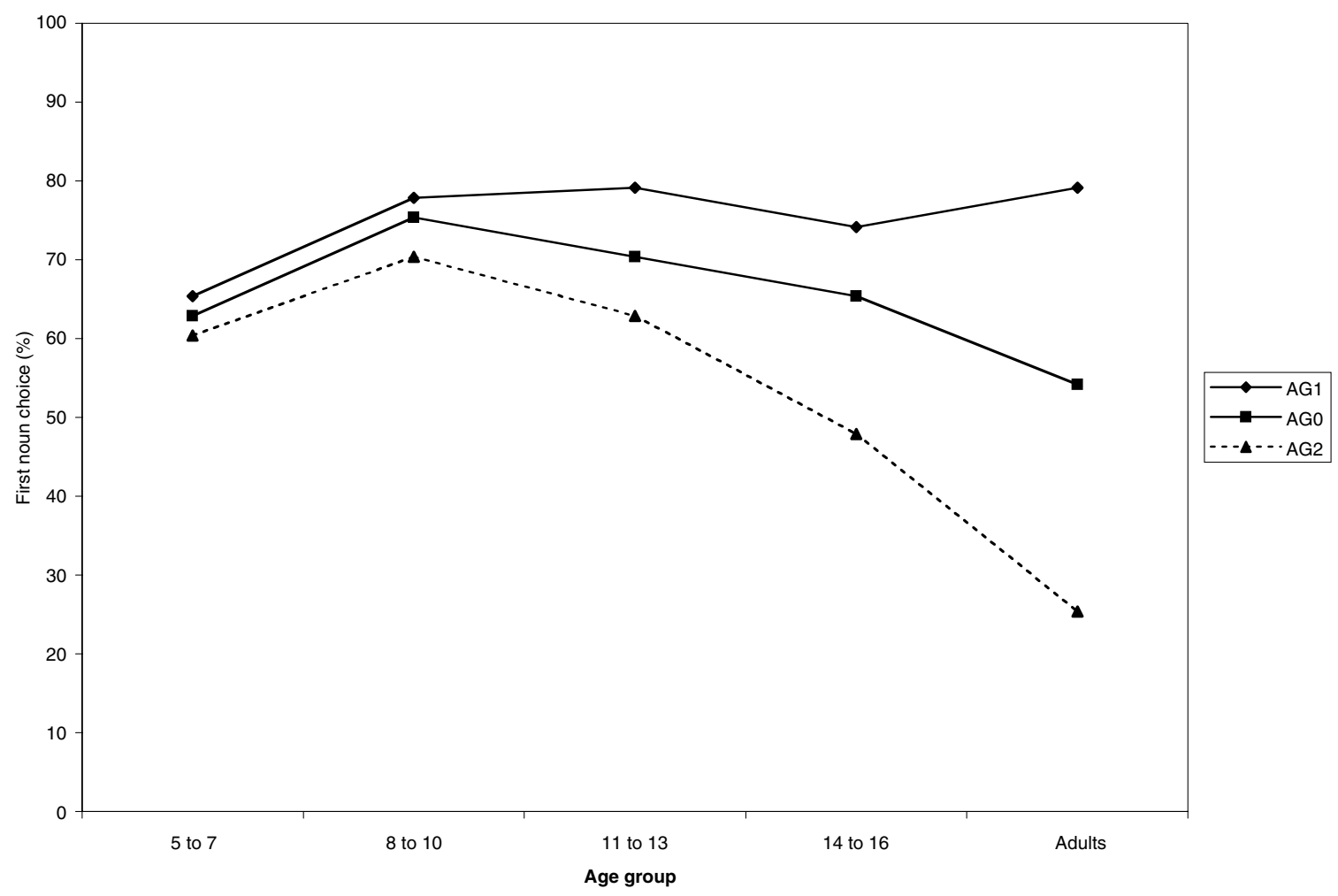

Figure 3. Effect of subject-verb agreement by age group.

Table 4. Mean percentages and standard deviations for first-noun choice by age group: Spanish

\begin{tabular}{|c|c|c|c|c|c|c|c|c|c|c|c|}
\hline \multirow[b]{2}{*}{ Word order } & \multirow{2}{*}{$\begin{array}{l}\mathrm{S}-\mathrm{V} \text { agreement } \\
\text { condition }\end{array}$} & \multicolumn{2}{|c|}{$5-7$ years } & \multicolumn{2}{|c|}{$8-10$ years } & \multicolumn{2}{|c|}{$11-13$ years } & \multicolumn{2}{|c|}{$14-16$ years } & \multicolumn{2}{|c|}{ Adults } \\
\hline & & $\%$ & SD & $\%$ & SD & $\%$ & SD & $\%$ & SD & $\%$ & SD \\
\hline \multirow[t]{3}{*}{ NVN } & AG0 & 79 & 24 & 92 & 14 & 95 & 16 & 93 & 16 & 94 & 16 \\
\hline & AG1 & 75 & 32 & 90 & 17 & 93 & 19 & 95 & 12 & 99 & 04 \\
\hline & AG2 & 77 & 22 & 89 & 14 & 87 & 23 & 76 & 32 & 54 & 39 \\
\hline \multirow[t]{3}{*}{ VNN } & AG0 & 59 & 30 & 70 & 30 & 66 & 29 & 64 & 30 & 52 & 33 \\
\hline & AG1 & 67 & 27 & 77 & 23 & 71 & 32 & 64 & 28 & 68 & 25 \\
\hline & AG2 & 49 & 25 & 59 & 28 & 53 & 32 & 45 & 31 & 21 & 28 \\
\hline \multirow[t]{3}{*}{ NNV } & AGO & 46 & 27 & 66 & 22 & 55 & 36 & 59 & 37 & 37 & 34 \\
\hline & AG1 & 51 & 23 & 71 & 29 & 72 & 30 & 78 & 29 & 78 & 28 \\
\hline & AG2 & 54 & 24 & 67 & 32 & 48 & 32 & 44 & 33 & 23 & 34 \\
\hline
\end{tabular}

In addition, the results of the second-order interaction of group by word order by subject-verb agreement confirmed that children's reliance on subject-verb agreement cues varies according to sentence type. Children attend to the subject-verb agreement cue particularly when interpreting sentences with non-canonical word orders. For example, in NVN sentences where the verb inflection agrees with the first noun (AG1) there is a steady increase in use of the subject-verb agreement cue across age groups, from $77 \%$ among 5 - to 7 -year-olds to $99 \%$ among adults. For VNN/AG2 sentences, the importance of the subject-verb agreement cue increases steadily with age, as children gradually develop a second-noun strategy. Interestingly, for sentences with a NNV/AG2 pattern, children continue to perform at random levels across the first four age groups; it is not until adulthood that they develop a second-noun strategy. Hence, adult bilinguals in this study make heavier use of subject-verb agreement cues for non-canonical than for canonical sentences. See the mean percentages and standard deviations for firstnoun choice in Spanish and English (Tables 4 and 5, respectively). 
Table 5. Mean percentages and standard deviations for first-noun choice by age group: English

\begin{tabular}{|c|c|c|c|c|c|c|c|c|c|c|c|}
\hline \multirow[b]{2}{*}{ Word order } & \multirow{2}{*}{$\begin{array}{l}\text { S-V agreement } \\
\text { condition }\end{array}$} & \multicolumn{2}{|c|}{$5-7$ years } & \multicolumn{2}{|c|}{$8-10$ years } & \multicolumn{2}{|c|}{$11-13$ years } & \multicolumn{2}{|c|}{$14-16$ years } & \multicolumn{2}{|c|}{ Adults } \\
\hline & & $\%$ & SD & $\%$ & SD & $\%$ & SD & $\%$ & SD & $\%$ & SD \\
\hline \multirow[t]{3}{*}{ NVN } & AG0 & 81 & 16 & 94 & 16 & 88 & 21 & 98 & 07 & 98 & 05 \\
\hline & AG1 & 82 & 15 & 88 & 21 & 93 & 20 & 96 & 12 & 99 & 04 \\
\hline & AG2 & 72 & 24 & 89 & 18 & 89 & 22 & 86 & 28 & 68 & 44 \\
\hline \multirow[t]{3}{*}{ VNN } & AG0 & 54 & 32 & 46 & 38 & 53 & 36 & 26 & 28 & 24 & 25 \\
\hline & AG1 & 56 & 29 & 57 & 31 & 59 & 30 & 43 & 38 & 50 & 36 \\
\hline & AG2 & 55 & 25 & 48 & 33 & 50 & 34 & 22 & 29 & 16 & 21 \\
\hline \multirow[t]{3}{*}{ NNV } & AG0 & 58 & 19 & 68 & 24 & 59 & 26 & 53 & 28 & 33 & 29 \\
\hline & AG1 & 61 & 19 & 70 & 28 & 68 & 22 & 58 & 28 & 60 & 34 \\
\hline & AG2 & 57 & 25 & 60 & 28 & 53 & 27 & 33 & 32 & 19 & 29 \\
\hline
\end{tabular}

Overall, these results indicate that young bilingual children are differentiating among strategies by language to some degree and are mostly taking advantage of local cues in both of their languages, whereas older bilinguals display an "in between" pattern of using distributed as well as local cues. The most important point is that these patterns look different from the strategies used by monolinguals in either language (see "General discussion" section below).

\section{Reaction time}

\section{Main effects}

The analysis of reaction time (RT) revealed a significant main effect of language $F(1,95)=419.40$, $p<.001$, and word order $F(2,190)=182.81, p<.001$, $M S E=414281.1923$. Overall, these bilinguals (collapsed across age groups) interpreted the NVN canonical sentences more quickly $(3440 \mathrm{~ms})$ than the VNN $(3787 \mathrm{~ms})$ or NNV sentences $(4150 \mathrm{~ms})$. The RT hierarchy was $\mathrm{NVN}<\mathrm{VNN}<\mathrm{NNV}$, with a difference of $710 \mathrm{~ms}$ in processing speed between NVN (fastest) and NNV (slowest) word orders.

\section{First- and second-order interactions}

The ANOVA also yielded significant first-order interactions for group by language, group by word order, and word order by subject-verb agreement, as well as higherorder interactions for group by word order by subject-verb agreement and for language by word order by subject-verb agreement.

\section{Word order}

The word order interactions point to interesting patterns across age groups. The group by word order interaction indicates how quickly each age group processes different sentence types. First, this interaction confirms the hier- archy for word order $(\mathrm{NVN}<\mathrm{VNN}<\mathrm{NNV})$. Regardless of age, these bilinguals prefer and process canonical sentences more efficiently than non-canonical sentences. Moreover, the higher-order interaction of group by word order by subject-verb agreement confirms the emergence of sensitivity to competing cues between word order and agreement, where 5- to 7-year-olds take longer to process NVN sentences than 8- to 10-year-old children do (see Figure 4a).

For non-canonical word order, both VNN and NNV sentences, there is a steady increase in RT based on subject-verb agreement cues across the three older groups (from the 11- to 13-year-olds to the college-age group; see Figures $4 \mathrm{~b}$ and $4 \mathrm{c}$ ). A clear developmental change takes place whereby older children begin to develop sensitivity to converging and competing cues, which SLOWS DOWN the process of sentence interpretation. A simple effect analysis confirms a significant difference between the older groups. Adult bilinguals responded most quickly when subject-verb agreement converged with word order and slowest when subject-verb agreement competed with canonical word order: $F(2,38)=29.00$, $p<0.001$, for NVN; $F(2,38)=6.74, p<0.001$ for VNN; and $F(2,38)=5.09, \mathrm{p}<0.01$ for NNV. Among the children, however, convergence effects speeded the processing of NVN sentences only in the 11- to 13-yearold group $-F(2,38)=11.53, p<0.001, M S E=46938.76$ - and the 14- to 16-year-old group $-F(2,38)=8.96, p<$ $0.001, M S E=51080.75$. Hence, the convergence of word order and subject-verb agreement cues does not appear to have a strong effect on the processing of SVO sentences until adolescence and adulthood.

\section{Language}

In terms of RTs in English and Spanish, there is a small interaction for group by language, with RTs significantly 


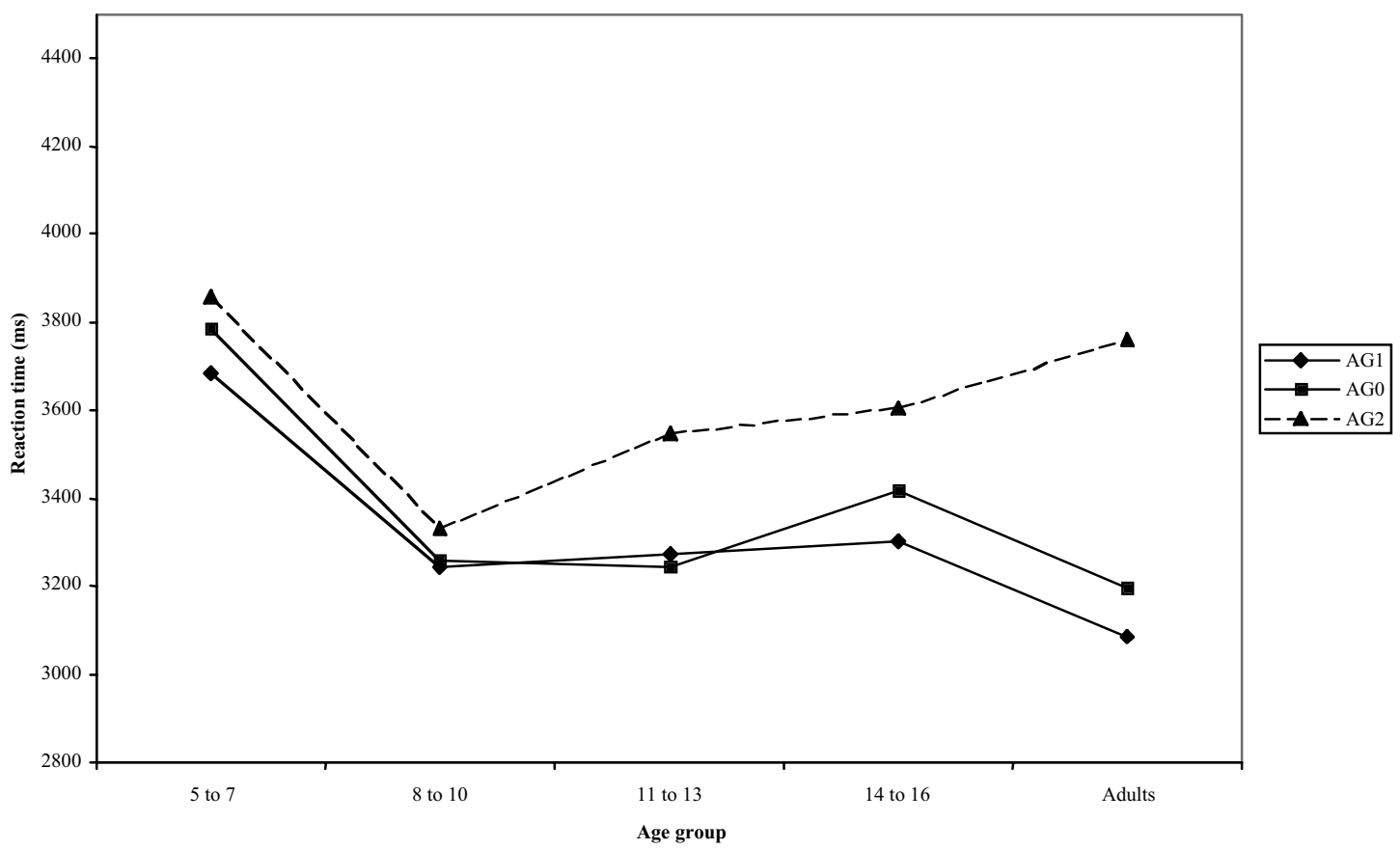

Figure 4a. Group by subject-verb agreement interaction for reaction time: NVN sentences.

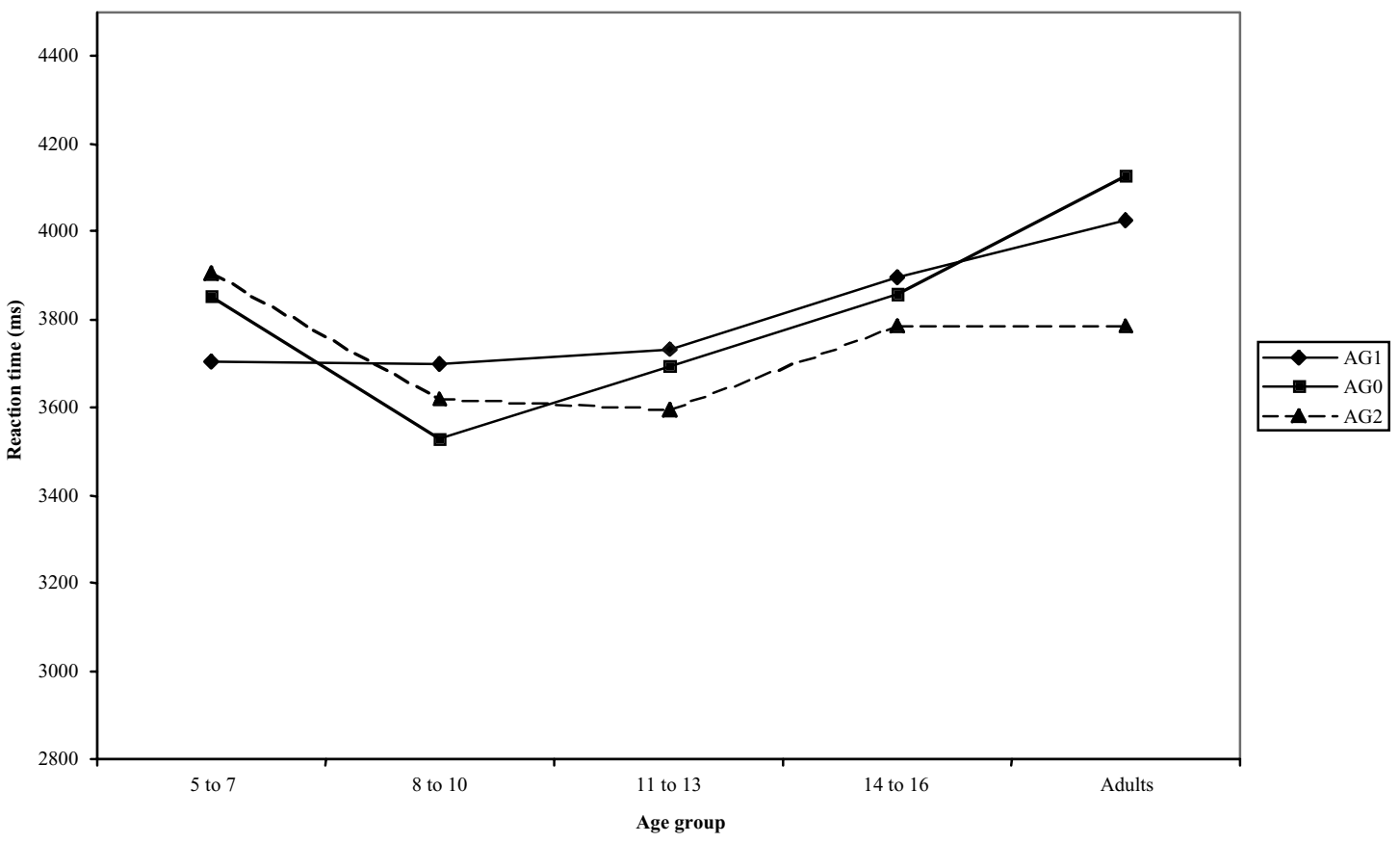

Figure $4 \mathrm{~b}$. Group by subject-verb agreement interaction for reaction time: VNN sentences.

decreasing between the 5- to 7-year-old group and the 8 - to 10 -year-old group, then steadily increasing across the older groups in both languages. The initial decrease in reaction time is more pronounced in Spanish than in English. This language difference is confirmed by the interaction of language by word order by subjectverb agreement, which shows a significant difference in response time between the two languages, with English sentences always being processed faster than Spanish sentences across all subject-verb agreement conditions. 


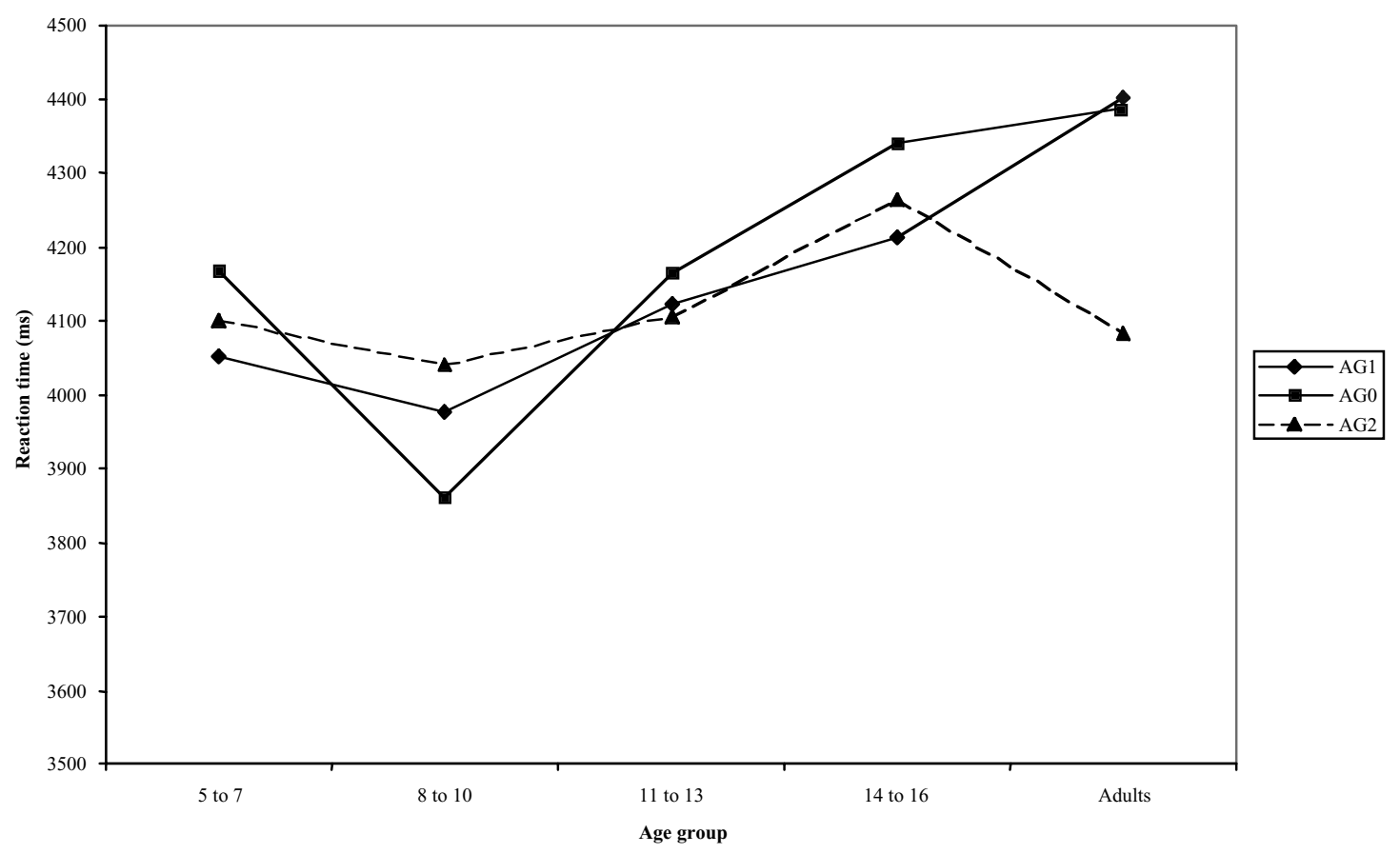

Figure 4c. Group by subject-verb agreement interaction for reaction time: NNV sentences.

This pattern replicates the findings of Hernández et al. (1994) that a significant difference in RT exists between Spanish and English. The RT difference may be due to the fact that Spanish stimulus words contained significantly more syllables than English words (an unavoidable result of the different syllable structure of Spanish; see Hernández et al., 1994, for further discussion); consequently requiring more time for interpretation. An alternative explanation for slower Spanish processing is the cost associated with processing non-canonical word orders, in conjunction with the fact that children are trying to pay attention to and consolidate subject-verb agreement cues in Spanish at a much earlier age than they do in English. This in turn makes older bilinguals slow down in Spanish because consolidating strategies carries a higher processing cost. Finally, RTs for Spanish stimuli obtained in the present study are similar to those obtained by Reyes (2003) for monolingual Spanish speakers across all age groups; in fact, when processing Spanish sentences with non-canonical word order, bilinguals are actually faster than their monolingual Spanish counterparts.

In summary, as they grow older, bilingual children are challenged to make use of all the grammatical cues available in their two languages and to develop the most efficient way of processing information in each language. Bilingual children gradually develop the ability to go beyond processing local cues to integrating and matching distributed cues. Although processing these distributed cues yields more accurate sentence interpretations, it does require more time, accounting the slower RTs for the older children. In the next section, we continue this discussion by comparing the pattern showed by bilinguals in this study with those found for monolingual children in previous studies.

\section{General discussion}

The current study was designed to determine the developmental profile of sentence interpretation in Spanish-English bilingual children, in terms of the relative strength of word order and subject-verb agreement cues at different ages. One important finding from our study is that first noun choice and RT follow different developmental patterns. As discussed below, in terms of agent choice, bilinguals' reliance on word order and subject-verb agreement cues falls IN BETWEEN the patterns shown by monolingual English and Spanish speakers. In contrast, for RT, bilinguals exhibit a certain degree of differentiation, resembling English monolingual speakers when interpreting English stimuli and Spanish monolingual speakers when interpreting Spanish stimuli. In the present study, bilinguals performed somewhere in between English and Spanish monolingual children in making use of word order strategies (local cues) before distributed cues such as subject-verb agreement. That is, bilinguals attended to subject-verb agreement cues at a later age than the typical Spanish monolingual speaker 
but an earlier age than the typical English monolingual speaker. Yet bilinguals are delayed in comparison to both English and Spanish monolinguals in the age at which they begin to use a second-noun strategy for interpreting NNV and VNN sentences. English monolinguals have a defined pattern of choosing the second noun as the agent by age seven for VNN sentences, and by age nine for NNV sentences (Von Berger et al., 1996). For Spanish monolinguals, the second-noun strategy appears by age 11 for both VNN and NNV sentences (Reyes, 2003). Bilinguals take longer to develop this strategy, not showing it until between 14 and 16 years of age. Compared with monolinguals in both languages, bilinguals demonstrate an in between pattern with regard to how they perceive and attend to different cues in each language (Hernández et al., 1994). The effect of competing strategies also increased with age as the participants attempted to sort and integrate cues to arrive at the most efficient processing strategy.

In terms of response times for different word orders, bilingual participants of all ages in our study followed the NVN < VNN < NNV hierarchy, which indicates that they are using canonical word order to interpret sentences. As bilingual children, Spanish monolinguals show the same response-time hierarchy, but by adulthood the pattern shifts to VNN $<$ NVN $<$ NNV (Reyes, 2003). This developmental shift is interpreted as indicating a reorganization of the processes by which decisions are made within each word order type. Specifically, adult listeners try to interpret the sentence as soon as they encounter the verb, because they assign the subject role to the noun that agrees with the verb. The fact that bilinguals do not show this shift suggests that they continue to rely primarily on word order when interpreting Spanish sentences because of its strong cue validity in English.

Another important result from this study is that RTs for interpreting non-canonical sentences slowed down with increasing age. We speculate that this slowdown in processing reflects an attempt to integrate converging and competing cues, suggesting that older bilinguals are doing some "hypothesis testing" to decide on the agent of a sentence. Children, in contrast, rely on word order, ignoring any competing subject-verb agreement cues, and therefore do not show any slowdown. Interestingly, Von Berger et al. (1996) observed a U-shaped increase in RT for NNV sentences in which 9- to 10-year-old English monolingual children took longer to process this sentence type than did either younger or older children. The authors suggested that this slowdown indicated a "hallmark" of development, in that this was the age at which children began integrating the competing cues in interpreting NNV sentences. We speculate that our participants' increase in RT around 11 years of age might reflect a similar "hallmark" in their development, indicating a process of consolidating the different strategies and testing the different possibilities in each language. These RT results can be interpreted as children exhibiting a certain degree of a differentiation. For Spanish stimuli, older participants performed similar to monolingual Spanish speakers by relying on agreement cues (Reyes, 2003); and for English stimuli, bilinguals' RTs had to do more with canonicity $(\mathrm{NVN}<\mathrm{NNV}<\mathrm{VNN})$ similar to Von Berger et al.'s (1996) results with English monolinguals.

In terms of agreement cues, bilinguals show an awareness of subject-verb agreement by age 8 and this effect increases steadily to age 11. However, this pattern, lags that observed for Spanish monolinguals, where a crossover from reliance on word order to reliance on agreement cues is seen among 8- to 10-year-olds. In contrast, English monolinguals show little sensitivity to agreement cues until adulthood (Von Berger et al., 1996). In this regard, it would appear that bilinguals are more advanced than their English monolingual counterparts in using agreement cues for sentence interpretation. These results reveal general similarities and differences between processes of bilingual and monolingual language development. Bilingual language acquisition is a very complex process through which bilinguals learn two languages and become adept at using them within the same time frame as it takes monolingual children to learn one language (Genesee, 2002).

In general, we found that typically developing bilingual and monolingual children follow different developmental patterns in their sentence interpretation strategies. That is, they do not simply perform like Spanish monolinguals or like English monolinguals. This difference is not only qualitative in nature, but quantitative too. One main difference is that bilinguals make relatively later use of subject-verb agreement cues. A variety of factors might account for this difference. One factor might be the demands on perceptual and working memory of processing morphological cues that are distributed across a sentence (Devescovi, D'Amico and Gentile, 1999). Specifically, to make use of distributed cues, children must remember the entire sentence until they have finished analyzing its meaning. Before they can compute agreement relationships, children need to develop the ability to analyze and remember each constituent of the sentence (see Mounoud, Vivani, Hauert and Guyon, 1985, for a similar type of shift in nonlinguistic tasks). In a recent study of young German children, Lindner (2003) found that difficulties in using agreement cues were linked to poor-short term memory skills in both typically developing children and children with impaired language. In the case of young bilingual children, we speculate that working memory limitations are overcome around 8 to 10 years of age allowing them to do long-distance morphological cue comparisons. For Spanish-English bilingual children, this shift might take longer than it does 
for Spanish monolingual children because, in addition to developmental changes related to working memory, they have to process and become grammatically competent in two linguistic systems. Other explanations, such as frequency of exposure to certain types of sentences, have also been considered in the literature. For example, children must encounter sentences in which word order and subject-verb agreement point to different actors in order to realize that agreement is the cue they should rely on in such cases (Golinkoff and Hirsh-Pasek, 1995). Such sentences are more likely to occur in Spanish than in English, so monolingual Spanish speakers are likely to have more experience interpreting them.

The findings of this study are partially consistent with other comparative studies of adult bilinguals (e.g. Wulfeck et al., 1986; Vaid and Pandit, 1991; Hernández et al., 1994). Naturally, the strategies bilingual children use might be meditated by developmental factors as well as factors related to their bilingualism (e.g. bilingual proficiency, age of exposure to L2), experimental task demands, and similarities in the syntactic structures of the two languages (e.g. word orders available in each language). Unfortunately, no study to date has established a direct association between sentence interpretation strategies and specific variables in bilinguals' language acquisition history. Future studies of bilingual processing must attempt more systematically to relate sentence interpretation patterns to individuals' bilingual acquisition variables.

Bilingual children in the United States often are misdiagnosed with a language delay or impairment relative to English monolinguals because they perform differently on language tasks (Bialystok 2001; Kester and Peña, 2002). Despite scientific evidence about the many advantages of childhood bilingualism ( $\mathrm{Li}, 2003)$, there is a common perception among educators that bilingual children are at a disadvantage. Consequently, it is important that researchers and educators not assume that monolingual and bilingual language processing is the same (see Grosjean, 1998, for further discussion), and we must continue identifying what is typical for bilingual development rather than comparing bilinguals against monolinguals. Specifically, we know that bilingual speakers are situated at different points along a multidimensional continuum that allows for "differences in type as well as degree at each level" of linguistic structure and each language skill (Paradis, 1986, p. xi).

On one hand, with regard to the SI task and $\mathrm{CM}$, bilinguals present a particular challenge because bilinguals need to integrate syntactic cues from two languages that may differ dramatically in their linguistic structure (Kilborn, 1989; Hernández et al., 1994). On the other hand, the application of such a model across monolingual and bilingual populations enables us to understand language universals and language- specific knowledge. Moreover, we believe it is important to compare sentence interpretation in adult and in child bilinguals in order to advance our knowledge and understanding of HOW a variety of linguistic cues help define which strategies bilingual children use on specific tasks (see $\mathrm{Li}, 2002$, for a similar argument).

A significant contribution of this study has been the application of the competition model to the domain of childhood bilingualism. A good model needs to be continuously revised to accommodate new data. In this case, we applied the CM to early emergent bilinguals at different ages, tracking their development and degree of awareness of word order and subjectverb agreement in real-time sentence processing. The results are in general consistent with the predictions of the CM. Specifically, each of the languages seems to influence the processing of the other, even though these children were interpreting sentences in only one language per session. Despite the effort that bilinguals make to "turn off" the non-relevant language, presumably via some monitoring mechanism not necessarily exclusive to language (Hernández, Martinez and Kohnert, 2000), there seems to be some residual activation of that linguistic system. The CM should account for this "residual" activation in bilinguals, which seems to affect their mapping of form to meaning and their development of complex interpretation strategies. ${ }^{4}$

To conclude, in this study we examined what factors have the strongest influence on children's development of syntactic strategies. A major goal of this research was to obtain the first sentence interpretation data with emergent bilingual children; such data can inform researchers as well as educators about the development of language comprehension strategies in this population. The results from this study indicate that a complex amalgamation and differentiation of linguistic rules actively present in both languages characterize the beginning stages of morphosyntactic development in bilingual children. It is our hope that the data provided here will contribute to strengthening crosslinguistic studies of bilingual language development. Future online studies with other bilingual populations should provide insights into their various patterns of sentence interpretation as well as possible implications for bilingual children's development of other linguistic skills, such as reading and writing.

\footnotetext{
4 Because of space limitations, we did not consider our findings in terms of Grosjean's (1998) bilingual mode continuum, which considers bilinguals' degree of activation of their two languages. Such an analysis might reveal other ways of interpreting our data.
} 
Appendix A. Nouns and verbs used in Spanish and English sentence stimuli

\begin{tabular}{lllll}
\hline \hline & Animate nouns & & & \multicolumn{2}{c}{ Verbs } \\
Spanish & English & & Spanish & English \\
\hline caballo & horse & acariciando & petting \\
cabra & goat & agarrando & grabbing \\
cebra & zebra & arrastrando & crawling \\
conejo & bunny & besando & kissing \\
elefante & elephant & comiendo & eating \\
gato & cat & correteando & chasing \\
oso & bear & empujando & pushing \\
pato & duck & golpeando & hitting \\
pajaro & bird & jalando & pulling \\
perro & dog & lamiendo & licking \\
puerco & pig & mordiendo & biting \\
vaca & cow & pelliscando & pinching \\
& & rasgunando & scratching \\
& & sacudiendo & bumping \\
& & tocando & touching \\
\hline \hline
\end{tabular}

Appendix B. Significant effects of the ANOVA analysis for choice by age group

\begin{tabular}{llll}
\hline \hline Age group & Main effect & $F$ & $p$ \\
\hline 5-7-year-olds & word order & $F(2,38)=22.05$ & $p<0.001$ \\
& S-V agreement & $F(2,38)=3.41$ & $p<0.043$ \\
8-10-year-olds & word order & $F(2,38)=10.80$ & $p<0.001$ \\
& S-V agreement & $F(2,38)=4.22$ & $p<0.023$ \\
& language $\times$ word order & $F(2,36)=6.70$ & $p<0.003$ \\
& word order $\times$ S-V agreement & $F(4,76)=2.83$ & $p<0.031$ \\
11-13-year-olds & word order & $F(2,38)=17.32$ & $p<0.001$ \\
& S-V agreement & $F(2,38)=9.98$ & $p<0.001$ \\
14-16-year-olds & language & $F(1,19)=12.11$ & $p<0.003$ \\
& word order & $F(1,19)=49.97$ & $p<0.001$ \\
& S-V agreement & $F(2,38)=16.69$ & $p<0.001$ \\
& language $\times$ word order & $F(2,38)=12.47$ & $p<0.001$ \\
College-age adults & language & $F(1,19)=6.76$ & $p<0.018$ \\
& word order & $F(2,38)=46.64$ & $p<0.001$ \\
& S-V agreement & $F(2,38)=43.07$ & $p<0.001$ \\
& language $\times$ word order & $F(2,38)=8.54$ & $p<0.001$ \\
& word order $\times$ S-V agreement & $F(4,76)=7.98$ & $p<0.001$ \\
\hline \hline
\end{tabular}


Appendix C. Significant effects of the ANOVA analysis for reaction time by age group

\begin{tabular}{llll}
\hline \hline Age group & Main effect & $F$ & $p$ \\
\hline 5-7-year-olds & language & $F(1,19)=48.52$ & $p<0.001$ \\
& word order & $F(2,38)=14.82$ & $p<0.001$ \\
8-10-year-olds & language & $F(1,19)=17.70$ & $p<0.001$ \\
& word order & $F(2,38)=34.02$ & $p<0.003$ \\
11-13-year-olds & language & $F(1,19)=143.36$ & $p<0.001$ \\
& word order & $F(2,38)=38.89$ & $p<0.001$ \\
& language $\times$ word order & $F(2,38)=3.81$ & $p<0.031$ \\
& word order $\times$ agreement & $F(4,76)=4.84$ & $p<0.002$ \\
& lang $\times$ word order $\times$ agreement & $F(4,76)=4.79$ & $p<0.002$ \\
$14-16$-year-olds & language & $F(1,19)=157.62$ & $p<0.001$ \\
& word order & $F(2,38)=43.47$ & $p<0.001$ \\
& word order $\times$ agreement & $F(4,76)=3.20$ & $p<0.017$ \\
College-age adults & language & $F(1,19)=205.86$ & $p<0.001$ \\
& word order & $F(2,38)=58.46$ & $p<0.001$ \\
& word order $\times$ agreement & $F(4,76)=21.80$ & $p<0.001$ \\
\hline \hline
\end{tabular}

\section{References}

ANSI [American National Standards Institute]. (1989). Specifications for audiometers (ANSI s3.6-1989). New York: ANSI.

Bates, E., Friederici, A. \& Wulfeck, B. (1987). Comprehension in aphasia: A cross-linguistic study. Brain and Language, 32, 19-67.

Bates, E. \& MacWhinney, B. (1989). Functionalism and the competition model. In B. MacWhinney \& E. Bates (eds.), The crosslinguistic study of sentence processing, pp. 3-76. New York: Cambridge University Press.

Bates, E., MacWhinney, B., Caselli, M. C., Devescovi, A., Natale, F. \& Venza, V. (1984). A cross-linguistic study of the development of sentence interpretation strategies. Child Development, 55, 341-351.

Bialystok, E. (2001). Bilingualism in development: Language, literacy and cognition. New York: Cambridge University Press.

Cohen, J., MacWhinney, B., Flatt, M. \& Provost, J. (1993). PsyScope: An interactive graphic system for designing and controlling experiments in the psychology laboratory using Macintosh computers. Behavior Research Methods, Instruments and Computers, 25, 257-271.

Deuchar, M. \& Quay, S. (2000). Bilingual acquisition: Theoretical implications of a case study. New York: Oxford University Press.

Devescovi, A. \& D'Amico, S. (2005). The competition model: Crosslinguistic studies of online processing. In M. Tomasello \& D. Slobin (eds.), Beyond nature-nurture: Essays in honor of Elizabeth Bates, pp. 165-191. Hillsdale, NJ: Lawrence Erlbaum Associates.

Devescovi, A., D’Amico, S. \& Gentile, P. (1999). The development of sentence comprehension in Italian: A reaction time study. First Language, 19, 129-163.
Devescovi, A., D’Amico, S., Smith, S., Mimica, I. \& Bates, E. (1998). The development of sentence comprehension in Italian and Serbo-Croatian: Local versus distributed cues. In D. Hillert (ed.), Syntax and semantics, vol. 31: Sentence processing: A cross-linguistic perspective, pp. 345-377. San Diego:Academic Press.

Dick, F., Wulfeck, B., Krupa-Kwiatkowski, M. \& Bates, E. (2004). The development of complex sentence interpretation in typically developing children compared with children with specific language impairments or early unilateral focal lesions. Developmental Science, 7, 360 377.

Dunn, L. M., Dunn, L. M., Robertson, G. J. \& Eisenberg, J. L. (1981). Peabody Picture Vocabulary Test-Revised. Circle Pines, MN: American Guidance Service.

Dunn, L. M., Padilla, E. R., Lugo, D. E. \& Dunn, L. M. (1986). Test de vocabulario en imágenes Peabody: Adaptación hispanoamericana. Circle Pines, MN: American Guidance Service.

Fraser, C., Bellugi, U. \& Brown, R. (1963). Control of grammar in imitation, comprehension, and production. Journal of Verbal Learning and Verbal Behavior, 2, 212-235.

Genesee, F. (2002). Portrait of the bilingual child. In V. Cook (ed.), Perspectives on the L2 user, pp. 170-196. Clevedon, England: Multilingual Matters.

Gernsbacher, M. A. (1990). Language comprehension as structure building. Hillsdale, NJ: Lawrence Erlbaum Associates.

Golinkoff, R. M. \& Hirsh-Pasek, K. (1995). Reinterpreting children's sentence comprehension: Toward a new framework. In P. Fletcher \& B. MacWhinney (eds.), Handbook of child language, pp. 430-461. Oxford: Blackwell.

Grosjean, F. (1998). Studying bilinguals: Methodological and conceptual issues. Bilingualism, 1 (2), 131-149. 
Hernández, A. E., Bates, E. \& Avila, L. X. (1994). Sentence interpretation in Spanish-English bilinguals: What does it mean to be in-between? Applied Psycholinguistics, 15, 417-466.

Hernández, A. E., Martinez, A. \& Kohnert, K. (2000). In search of the language switch: An fMRI study of picture naming in Spanish-English bilinguals. Brain \& Language, 73, 421431.

Hernández, A. E., Sierra, I. \& Bates, E. (2000). Sentence interpretation in bilingual and monolingual Spanish speakers: Grammatical processing in a monolingual mode. Spanish Applied Linguistics, 4 (2), 179-213.

Johnson-Laird, P. N. (1983). Mental models. Cambridge, MA: Harvard University Press.

Kail, M. (1989). Cue validity, cue cost, and processing types in French sentence comprehension. In B. MacWhinney \& E. Bates (eds.), The crosslinguistic study of sentence processing, pp. 77-117. New York: Cambridge University Press.

Kail, M. (2004). On-line grammaticality judgments in French children and adults: a crosslinguistic perspective. Journal of Child Language, 31, 713-737.

Kail, M. \& Charvillat, A. (1988). Local and topological processing in sentence Comprehension by French and Spanish children. Journal of Child Language, 15, 637-662.

Kaplan, E., Goodglass, H. \& Weintraub, S. (1983). Boston naming test. Philadelphia: Lea and Febiger.

Kester, E. \& Peña, E. (2002). Language ability assessment of Spanish-English bilinguals: Future directions. Practical Assessment, Research \& Evaluation, 8 (4); $<\mathrm{http} / /$ pareonline.net/getvn.asp? $\mathrm{v}=8 \& \mathrm{n}=4>$.

Kilborn, K. (1989). Sentence processing in a second language: The timing of transfer. Language and Speech, 32, 123.

Kilborn, K. (1994). Learning a language late: Second language acquisition in adults. In M. A. Gernsbacher (ed.), Handbook of psycholinguistics, pp. 971-944. San Diego: Academic Press.

Kohnert, K., Bates, E. \& Hernández, A. (1999). Balancing bilinguals: Lexical-semantic production and cognitive processing in children learning Spanish and English. Journal of Speech, Language, and Hearing Research, 42, 1400-1413.

Lanza, E. (1997). Language mixing in infant bilingualism. Oxford: Clarendon Press.

Li, P. (1996). The temporal structure of spoken sentence comprehension in Chinese. Perception and Psychophysics, 58, 571-586.

Li, P. (2002). Bilingualism is in dire need of formal models. Bilingualism, 5 (3), 213.

Li, P. (2003). Raising children bilingual: Should we, and when? Contemporary Psychology, 48, 667-669.

Lindner, K. (2003). The development of sentence-interpretation strategies in monolingual German-learning children with and without specific language impairment. Linguistics, 41, 213-254.

Liu, H., Bates, E. \& Li, P. (1992). Sentence interpretation in bilingual speakers of English and Chinese. Applied Psycholinguistics, 13, 451-484.
MacWhinney, B., Pleh, C. \& Bates, E. (1985). The development of sentence interpretation in Hungarian. Cognitive Psychology, 17, 178-209.

McDonald, J. (1986). The development of sentence comprehension strategies in English and Dutch. Journal of Experimental Child Psychology, 41, 317-335.

Mounoud, P., Vivani, P., Hauert, C. A. \& Guyon, J. (1985). Development of visuomanual tracking in 5- to 9-year-old boys. Journal of Experimental Child Psychology, 40, 115132.

Paradis, J. (1986). Foreword. In J. Vaid (ed.), Language processing in bilinguals: Psycholinguistic and neuropsychological perspectives, pp. xi-xii. Hillsdale, NJ: Lawrence Erlbaum Associates.

Pearson, B. Z. \& Fernandez, S. (1994). Patterns of interaction in the lexical development in two languages of bilingual infants. Language Learning, 44, 617-653.

Reyes, I. (2003). A study of sentence interpretation in Spanish monolingual children. First Language, 23, 285-309.

Reyes, I. (2004). Functions of code-switching in schoolchildren's conversations. Bilingual Research Journal, 28 (1), 77-98.

Sebastian, E. \& Slobin, D. I. (1994). Development of linguistic forms: Spanish. In R. A. Berman \& D. I. Slobin (eds.), Relating events in narrative: A crosslinguistic developmental study. Hillsdale, pp. 239-284. Hillside, NJ: Lawrence Erlbaum Associates.

Serratrice, L., Sorace, A. \& Paoli, S. (2004). Crosslinguistic influence at the syntax-pragmatics interface: Subjects and objects in English-Italian bilingual and monolingual acquisition. Bilingualism, 7, 183-205.

Slobin, D. I. (1966). Grammatical transformations in childhood and adulthood. Journal of Verbal Learning and Verbal Behavior, 5, 219-227.

Slobin, D. I. (1979). Psycholinguistics (2nd ed.). Glenview, IL: Scott, Foresman.

Slobin, D. I. (1985). The cross-linguistic study of language acquisition. Hillsdale, NJ: Lawrence Erlbaum Associates.

Slobin, D. I. \& Bever, T. G. (1982). Children's use of canonical sentence schemas: A crosslinguistic study of word order and inflections. Cognition, 12, 229-265.

Thal, D. J. \& Flores, M. (2001). Development of sentence interpretation strategies by typically developing and latetalking toddlers. Journal of Child Language, 28, 173-193.

Vaid, J. \& Pandit, R. (1991). Sentence interpretation in normal and aphasic Hindi speakers. Brain and Language, 41, 250 274.

Von Berger, E., Wulfeck, B., Bates, E. \& Fink, N. (1996). Developmental change in real-time sentence processing. First Language, 16, 193-222.

Wulfeck, B., Juarez, L., Bates, E. \& Kilborn, K. (1986). Sentence interpretation strategies in healthy and aphasic bilingual adults. In J. Vaid (ed.), Language processing in bilinguals: Psycholinguistic and neurological perspectives, pp. 199220. Hillsdale, NJ: Lawrence Erlbaum Associates.

Received January 17, 2003

Revision received August 4, 2004 and March 24, 2005

Accepted May 3, 2005 